\title{
BMJ Open Exploring trust in religious leaders and institutions as a mechanism for improving retention in child malnutrition interventions in the Philippines: a retrospective cohort study
}

\author{
Lincoln Leehang Lau (D) , ${ }^{1,2,3}$ Warren Dodd (D) , ${ }^{3}$ Han Lily Qu, ${ }^{2}$ Donald C Cole ${ }^{1}$
}

To cite: Lau LL, Dodd W, Qu HL, et al. Exploring trust in religious leaders and institutions as a mechanism for improving retention in child malnutrition interventions in the Philippines: a retrospective cohort study. BMJ Open 2020;10:e036091. doi:10.1136/ bmjopen-2019-036091

- Prepublication history and additional material for this paper are available online. To view these files, please visit the journal online (http://dx.doi. org/10.1136/bmjopen-2019036091).

LLL and WD are joint first authors.

Received 06 December 2019 Revised 10 July 2020

Accepted 15 July 2020

A) Check for updates

(C) Author(s) (or their employer(s)) 2020. Re-use permitted under CC BY-NC. No commercial re-use. See rights and permissions. Published by BMJ.

${ }^{1}$ Dalla Lana School of Public Health, University of Toronto, Toronto, Ontario, Canada ${ }^{2}$ International Care Ministries, Manila, NCR, Philippines ${ }^{3}$ School of Public Health and Health Systems, University of Waterloo, Waterloo, Ontario, Canada

\section{Correspondence to}

Dr Lincoln Leehang Lau; lincoln.lau@utoronto.ca and Dr Warren Dodd; wdodd@uwaterloo.ca

\section{ABSTRACT}

Objectives In the context of persistent child malnutrition in the Philippines, the objective of this study was to examine how different dimensions of trust affected programme retention and physiological outcomes when a faith-based organisation (FBO) addressed moderate and severe acute malnutrition among children from households experiencing extreme poverty.

Setting We retrospectively analysed survey data collected by International Care Ministries (ICM) in 2012-2013 across 150 communities in eight provinces (Negros Oriental, Negros Occidental, Bohol, Palawan, Sarangani, South Cotabato, Sultan Kudarat and Zamboanga del Norte) of the Philippines.

Study participants Caregivers of 1192 children experiencing moderate acute malnutrition and severe acute malnutrition between the ages of 6 and 60 months.

Intervention A 16-week child malnutrition treatment programme called Malnourished Child Outreach offered by ICM in partnership with local religious leaders and institutions.

Primary and secondary outcome measures Programme dropout and weight-for-height z-score (WHZ) at the end of the programme for enrolled children were the two outcomes of interest. A logistic mixed-effects model was built to assess factors associated with programme dropout and a linear mixed-effects model for factors associated with WHZ at the end of the programme.

Results Trust in religious leaders or institutions $(-0.87$ $(95 \% \mathrm{Cl}:-1.43,-0.26))$ was negatively associated with programme dropout, suggesting that with increasing levels of trust, decreasing proportions of children dropped out of treatment. Retention in the programme led to improved WHZ among participating children $(-0.38(95 \% \mathrm{Cl}:-1.43$, $0.26)$ ). Various measures of social capital, including trust in religious and public institutions, were not associated with WHZ at the end of the programme.

Conclusions Leveraging pre-existing trust in religious leaders and institutions among households experiencing extreme poverty is one way that ICM, and potentially other FBOs, can promote retention in child nutrition interventions among vulnerable populations.
Strengths and limitations of this study

- The study was conducted in a unique setting for examining the underlying mechanisms associated with the retention of children enrolled in malnutrition interventions delivered by a faith-based organisation to children in households experiencing extreme poverty.

- The retrospective cohort design of this study is an opportunistic and practical approach for exploring the role of religious leaders in health interventions.

- Linear and logistic modelling is used to explore the pathways through which social capital shapes nutrition outcomes in malnourished children who concurrently experience extreme poverty in the Philippines.

- Multi-level modelling allows analyses to account for the hierarchical structure of variables that are present in the communities where the child malnutrition intervention described in this study took place.

- While multiple factors were considered to examine treatment outcomes in child malnutrition interventions, the study could not account for all potential confounders within the complex social settings where the study was conducted.

\section{INTRODUCTION}

Faith-based organisations (FBOs) play a critical role in delivering healthcare in low resource settings. Compared with public health facilities and providers, programmes and interventions offered by FBOs in some settings may have increased geographical and socioeconomic coverage, greater social and physical capital, and more flexible governance and funding structures. ${ }^{1-3}$ Additionally, many FBOs focus exclusively on serving poor and vulnerable people, addressing limited reach of public health systems. ${ }^{45}$ As a result, partnerships between public health institutions and FBOs are increasingly being viewed as an important strategy for improving healthcare 
access and health outcomes in low-and-middle-income countries. ${ }^{36}$

Despite the critical role that FBOs play in delivering healthcare in low resource settings, the capabilities and assets of some FBOs have been underused and underexplored. ${ }^{17}$ This underutilisation may be influenced by concerns that the religious underpinnings of FBOs contradict human rights and associated health outcomes, such as in the case of sexual and reproductive health or vaccination campaigns. ${ }^{18}$ Challenges also exist with the alignment of health priorities between FBOs and national health systems, inconsistent funding and governance of local FBOs, and their limited capacity to adapt to changing health systems. ${ }^{27}$ Additionally, there are gaps in evidence with regard to the quantity and distribution of FBOs, the quality of care provided by these organisations, and the factors that contribute to the success of programmes and interventions led by FBOs. ${ }^{157}$

Collaboration with local religious leaders and their institutions is one factor contributing to the success of health interventions implemented by FBOs. Many communities view religious leaders and institutions as a trustworthy and credible source of health advice and information, with research finding that religious leaders' opinions can strongly influence social and behavioural norms. ${ }^{9-12}$ As embedded members of their communities, local religious leaders frequently have intimate knowledge of existing histories, networks and sociocultural dynamics influencing individual and community health and well-being, which positions them as important resources for health interventions. ${ }^{13}$ As such, local religious leaders have been identified as change agents key to promoting health awareness, disseminating health education, developing and implementing health interventions, and influencing health-seeking behaviour. ${ }^{9-12} 1415$

Turning to the Philippines, recent impressive national economic growth has not translated into a meaningful reduction in chronic and acute child malnutrition. According to the 2015 National Nutrition Survey, between 2013 and 2015, the national prevalence of under-five underweight increased from $20 \%$ to $21.5 \%$ and underfive stunting increased from $30.3 \%$ to $33.4 \% .{ }^{16}{ }^{17}$ Prevalence of under-five wasting decreased slightly from $8.0 \%$ to $7.1 \%$ over this time period..$^{18}$ Concurrently, an estimated $8.1 \%$ of the total population lived in extreme poverty in $2015,{ }^{19}$ which represents a high national-level prevalence of poverty when compared with neighbouring Asia-Pacific countries. ${ }^{20}$

Achieving universal healthcare with an emphasis on health equity is a core mandate for the Department of Health in the Philippines. However, gaps remain in service provision for households that simultaneously experience extreme poverty and child malnutrition, which is especially problematic in cases of moderate acute malnutrition (MAM) and severe acute malnutrition (SAM). Where such service gaps exist, civil society organisations including FBOs, in addition to multi-lateral institutions, such as the World Food Programme and UNICEF, may step in to provide complementary care. Notably, there is increasing attention and interest in the longstanding role of FBOs in delivering healthcare to complement existing public healthcare infrastructure. ${ }^{1421}$

Trust, social relationships, cooperation and reciprocity, or social capital, play a critical role in the well-being of income poor households. ${ }^{22}{ }^{23}$ Social capital is theorised to have both an internal (via bonding relationships between members of a group) ${ }^{24}$ and an external (via bridging connections to external supports beyond a group) function. ${ }^{25}$ In terms of external functionality, trust in healthcare providers and institutions is an important mechanism underlying healthcare decisions and treatment adherence. ${ }^{26}$ Additionally, trust in healthcare personnel, a facility or the healthcare system more broadly is often cited as a determinant of health-seeking behaviour and connected with positive health outcomes. ${ }^{27-29}$ What is less clear is how trust in religious leaders and institutions in partnership with FBOs delivering health interventions interacts with other structural and socioeconomic barriers to influence healthcare access and use for households that experience extreme poverty. Moreover, there is limited research examining how trust in the religious leaders and institutions associated with these organisations influences subsequent retention of participants within programme interventions aimed at addressing childhood malnutrition.

To engage with these questions, we retrospectively analysed data collected by a Philippine FBO (International Care Ministries; ICM) that delivered a programme to address MAM and SAM in children living in ultrapoor households (defined as less than US $\$ 0.50$ per person per day) in partnership with local religious leaders and institutions. The objective of this study was to examine how different dimensions of trust, in addition to other indicators of social capital, affected programme retention and physiological outcomes among participating children.

\section{METHODS}

\section{Intervention}

ICM implemented three rounds of a treatment programme targeted at acute child malnutrition from 2012 to 2013. The programmes ran from June 2012 to September 2012, October 2012 to January 2013 and February 2013 to May 2013. A total of 1219 children from 1010 households representing 150 unique communities were treated and surveyed across the provinces of Negros Oriental, Negros Occidental, Bohol, Palawan, Sarangani, South Cotabato, Sultan Kudarat and Zamboanga del Norte in the Philippines.

The treatment programme, called Malnourished Child Outreach (MCO), was a 16-week site-based feeding programme for moderately and severely wasted children between the ages of 6 and 60 months. SAM was defined as weight-for-height z-score (WHZ) $\leq-3$ SD from median reference values, and MAM was defined as WHZ $\leq-2$ SD and $>-3$ SD from reference values according to 
international standards. ${ }^{30}$ ICM initiated programmes when a local volunteer pastor was able to identify 10-15 malnourished children within the vicinity of his or her church. Pastors, who were associated with various Protestant denominations, consulted a list of malnourished children kept by local health centres. These pastors then conducted house-to-house visits to complete enrolment. All malnourished children were eligible for enrolment, regardless of religious affiliation. Once the enrolment target was met, ICM would provide the food, protocol and staff to complement the pastor and church volunteers for programme delivery. In a fixed location in or near the volunteer pastors' church, ICM staff would prepare a single meal which was fed to children, assisted by their caregivers, for 5 days per week over a 16 -week period. The product used for the feeding programme was a micronutrient fortified rice-based soy blend which required cooking. Other programme components included deworming, a health assessment, weight monitoring, weekly health, nutrition, health education for caregivers and home-based vegetable gardening. Children who remained SAM at the end of the 16 weeks were referred to local government clinics for additional assessment and management.

\section{Study design}

This was an opportunistic study, retrospectively designed to use household surveys that ICM administered to the caregivers of the children enrolled in the MCO programme. As a result, all households with complete treatment outcome data were included as study participants within the retrospective cohort. To understand household characteristics, caregivers of enrolled children were interviewed at baseline by trained enumerators prior to the start of the treatment. Written informed consent was obtained at two points in time: first from the guardian when children were enrolled into the programme, and again at the start of the baseline survey. Questions covered household demographics, economic well-being, general health, asset-based poverty measures and hygiene. Indicators of pre-existing social capital were also explored including group membership, trust in local religious leaders and institutions, and trust in local public healthcare facilities (online supplementary appendix 1 ). These survey data were linked with weekly monitoring and outcomes data. Monitoring data captured weekly weights, number of feeding sessions attended, and outcomes included treatment completion (did not drop out), and discharge weight and height measures (online supplementary appendix 2).

\section{Patient and public involvement}

We did not include patient and public involvement in the design, conduct or analysis in this study. The preliminary findings have been discussed with carers and providers, with plans to disseminate implications to the wider nutrition community in the Philippines.

\section{Statistical approach}

There were two outcomes of interest: (1) dropout (categorical variable), defined as children who were withdrawn from the programme by their caregiver or missed repeated feeding sessions and lost to follow-up and (2) WHZ at the end of the programme (continuous variable). Independent variables were at both the individual/ household level and the community level (see table 1). The geographical type of community was categorised into Urban Slum, Rural Plain/Rural Slum, Rural Mountain, or Coastal/Fishing by ICM staff. We adopted and revised the measure for intensity of poverty, or $A$, as defined in the Alkire-Foster Method for measuring multi-dimensional poverty. ${ }^{31}$ Intensity of poverty is defined as the average proportion of indicators in which a household is deprived in, and a household is categorised as 'experiencing poverty' if they are deprived in at least one-third of the weighted indicators. One important feature of $A$ is the ability to quantitatively estimate poverty at the household level, and therefore include in model building (see online supplementary appendix 3 for more detail).

The hierarchical structure in which this intervention was set (households in communities) required the utilisation of mixed-effects modelling to explore the potential causal relationship of varied dimensions of social capital at the household and the geographical context at the community level.

For both outcomes, a series of covariates such as sex of caregiver, age of caregiver, household size and others were explored. The most parsimonious models that minimise deviance were chosen. All analyses were conducted using R (V.3.2.3). Detailed statistical methods are described in the supplementary materials (online supplementary appendix 3).

\section{RESULTS}

A total of 1219 treated children were included in this study, however 27 cases had incomplete treatment records and an additional 176 cases had incomplete weight data. As a result, final logistic analyses included 1192 children, while the linear analyses included 1016 children. Significant differences were not detected between the logistic and linear cases at baseline (tables 2 and 3 ). The average age of children was 33.13 months and 32.96 months in the logistic and linear models, respectively. The sex of the children was balanced, while measures of trust were found to be slightly higher for religious leaders or churches than for local government (barangay) and neighbours.

The final mixed-effects model on dropout included sex, three measures of social capital, intensity of poverty (A) and a series of random effects (table 4). In the most parsimonious model, which includes predictors and interaction terms, the caregiver's trust in religious leaders or church was negatively associated with dropout $(-0.87$ (95\% CI: $-1.43,0.26)$ ), suggesting that each increased level of satisfaction or trust was associated with a decreased proportion of dropouts from the treatment programme. 
Table 1 List of model outcomes and variables

\begin{tabular}{|c|c|c|c|}
\hline Level & Item & Variable & Description \\
\hline \multicolumn{4}{|l|}{ Logistic model } \\
\hline Outcome & Dropout & $\pi_{\mathrm{ij}}$ & Binary result if child dropped out of the programme \\
\hline \multirow{5}{*}{1 (household level) } & $\begin{array}{l}\text { Trust in religious } \\
\text { leader or church }\end{array}$ & $X_{\text {IIIIj }}$ & $\begin{array}{l}\text { How much do you trust your religious leaders or church? (5-point } \\
\text { Likert Scale) }\end{array}$ \\
\hline & Trust in neighbours & $X_{\mathrm{VIlij}}$ & How much do you trust your neighbours? (5-point Likert Scale) \\
\hline & Family satisfaction & $X_{\mathrm{VIIIIj}}$ & How satisfied are you with your family life? (5-point Likert Scale) \\
\hline & $\mathrm{WHZ}_{1}$ & $X_{\mathrm{Vij}}$ & Baseline weight-for-height z-score of the child \\
\hline & $A$ & $X_{\mathrm{Vlij}}$ & Intensity of poverty \\
\hline \multirow{5}{*}{1 (household level) } & Age & $X_{\text {IIij }}$ & Age of the child at baseline \\
\hline & $\begin{array}{l}\text { Trust in religious } \\
\text { leader or church }\end{array}$ & $X_{\text {IIIIj }}$ & $\begin{array}{l}\text { How much do you trust your religious leaders or church? (5-point } \\
\text { Likert Scale) }\end{array}$ \\
\hline & Trust in barangay & $X_{\mathrm{IVij}}$ & $\begin{array}{l}\text { How much do you trust your local barangay? (5-point Likert } \\
\text { Scale) }\end{array}$ \\
\hline & $\mathrm{WHZ}$ & $X_{\mathrm{Vij}}$ & Baseline weight-for-height z-score of the child \\
\hline & $A$ & $X_{\text {Vij }}$ & Intensity of poverty \\
\hline 2 (community level) & Geography & $Z_{j}$ & Geographical type of the community \\
\hline
\end{tabular}

*A 'barangay' is the smallest administrative division in the Philippines and represents the local government.

WHZ, weight-for-height z-score.

The caregiver's trust in the local barangay was associated with dropout in the reverse direction (0.81 (95\% CI: 0.22, $1.40)$ ), interpreted as those with higher levels of trust in local government dropping out more. These estimates reveal that trust in specific entities can be correlated with likelihood of dropout in opposing directions, depending on whom or where the trust is directed towards. Households reporting a higher intensity of poverty were also significantly linked with a lower rate of dropout $(-4.21$ (95\% CI: $-7.76,0.66)$ ).
The estimates in table 5 describe the results of mixedeffects modelling on $\mathrm{WHZ}_{2}$ as an outcome. The intercept of Model 1 (intercept only) estimated at -0.38 is the unadjusted decrease in average WHZ at discharge for children treated across all communities. The direction of this coefficient suggests that on average, children that completed the programme experienced movement toward normal WHZ. The intraclass correlation coefficient calculated for the model was 0.27 , representing that $27 \%$ of variance in $\mathrm{WHZ}_{2}$ is attributed to the community

Table 2 Baseline values of continuous independent variables

\begin{tabular}{|c|c|c|c|c|}
\hline \multirow[b]{2}{*}{ Variable } & \multicolumn{2}{|c|}{$\begin{array}{l}\text { Logistic model } \\
(n=1192)\end{array}$} & \multicolumn{2}{|c|}{$\begin{array}{l}\text { Linear model } \\
(n=1016)\end{array}$} \\
\hline & Mean & SD & Mean & SD \\
\hline $\mathrm{WHZ}_{1}$ & -2.42 & 1.00 & -2.42 & 1.01 \\
\hline$A$ & 0.36 & 0.22 & 0.37 & 0.21 \\
\hline Trust in neighbours & 3.91 & 0.92 & - & - \\
\hline Family satisfaction & 3.77 & 1.02 & - & - \\
\hline
\end{tabular}

WHZ, weight-for-height z-score. 


\begin{tabular}{lll}
\hline $\begin{array}{l}\text { Table } 3 \text { Baseline values of categorical independent } \\
\text { variables }\end{array}$ & $\mathbf{n}$ & $\%$ \\
\hline Variables & 585 & 49 \\
\hline $\begin{array}{l}\text { Logistic model } \\
\quad \text { sex (male) }\end{array}$ & 607 & 51 \\
$\quad$ sex (female) & & \\
Linear model & 504 & 50 \\
$\quad$ sex (male) & 512 & 50 \\
$\quad$ sex (female) & & \\
Geographical types & 225 & 19 \\
$\quad$ Urban slum & 305 & 26 \\
$\quad$ Rural plain/rural slum & 487 & 41 \\
$\quad$ Rural mountain & 175 & 15 \\
\hline Coastal/fishing & & \\
\hline
\end{tabular}

level covariate of geographical type. Age was negatively correlated to $\mathrm{WHZ}_{2}$, indicating that older children experienced diminished growth compared with younger children. $\mathrm{WHZ}_{1}$ was positively correlated with $\mathrm{WHZ}_{2}$, which can be interpreted as children who were closer to normal weight at the beginning of the programme achieved a higher $\mathrm{WHZ}_{2}$ by the end of the programme. Intensity of poverty was also found to be significant. The coefficient of -0.47 in Model 3 is not directly interpretable, but the direction shows that greater intensity of household poverty was linked to lower $\mathrm{WHZ}_{2}$. Neither measure of caregiver trust (in religious leaders and church, or local government) was found to be significantly correlated with $\mathrm{WHZ}_{2}$. Additional modelling using centred coefficients to increase parsimony were conducted but are not reported as they were not found to improve the model.

\section{DISCUSSION}

While social networks are critical for the poorest households to access and navigate health and social services, the multi-dimensional vulnerabilities and exclusion that these households often experience make them the least able to effectively leverage relationships for household benefit. ${ }^{32}{ }^{33}$ This reality is evident in the Philippines, with a previous study demonstrating that poor households in a slum area with few social ties had less access to key municipal services, such as water. ${ }^{34}$ We suggest that when households experiencing extreme poverty trust local religious leaders and institutions (ie, local pastors and churches), they are more likely to remain enrolled in services provided through these networks. Thus, an opportunity exists for these actors to improve the delivery of health and social services. In addition to trust, we recognise that need also drives programme retention as households with the greatest intensity of poverty were the least likely to drop out of the programme offered by ICM.

There is a lack of consensus regarding the effectiveness of FBOs to deliver primary healthcare across low-resource settings among populations experiencing extreme poverty. ${ }^{35-38}$ Similarly there is a need for more information to understand if and under what conditions these organisations contribute to positive health outcomes. ${ }^{5}$ However, the trusting relationships that FBOs as well as religious leaders and institutions often hold in the communities in which they are embedded in and operate have been highlighted as an important feature and possible mechanism to ensure effective and meaningful service delivery. ${ }^{9}{ }^{13} 15$ The logistic mixed effects model showed a significant negative association $(-0.87$ (95\% CI: -1.43, 0.26)) between dropout and caregiver trust in religious leaders and institutions, confirming that this type of trust was a determinant of retention among participants attending the MCO programme administered by ICM in partnership with local religious leaders. This model of service delivery provides an example of a potential strategy FBOs in the Philippines, and elsewhere, can use to contribute to addressing acute child malnutrition- namely, leveraging trust in religious leaders and institutions prior to the intervention among households experiencing extreme poverty to promote health programme retention among vulnerable populations.

High levels of structural social capital (ie, group membership and the presence of social support) among caregivers have been hypothesised to contribute positively to the nutritional status of their children. Structural social capital is thought to lead to access to food resources, improved living conditions, access to knowledge networks and access to health services, which in turn, may create conditions of increased food security, reduced childhood illness and an increased ability to care for children. ${ }^{39} \mathrm{In}$ our study, initial weight-for-height, age at baseline and the intensity of household poverty were associated with physiological outcomes among acutely malnourished children following treatment. Additionally, children who completed the treatment programme experienced movement toward a normal WHZ. However, various structural dimensions of social capital among caregivers were not directly associated with improved physiological outcomes in acutely malnourished children. This finding pushes us to more closely examine the relationship between participant retention in malnutrition interventions and structural social capital as the mechanism through which structural social capital influences child nutrition outcomes.

This study faced several limitations. First, the findings represent the outcomes of one programme implemented by a specific Christian FBO in the Philippines and its partnership with Protestant religious leaders and churches, which might not be readily generalisable to other settings. Second, the data collected were limited to enumerators directly asking caregivers of children in income poor communities to respond to questions about their trust in individuals and groups connected to the organisation providing them with services or resources. Third, the models presented were restricted to exploring the covariates included in the baseline survey. Fourth, there was the 


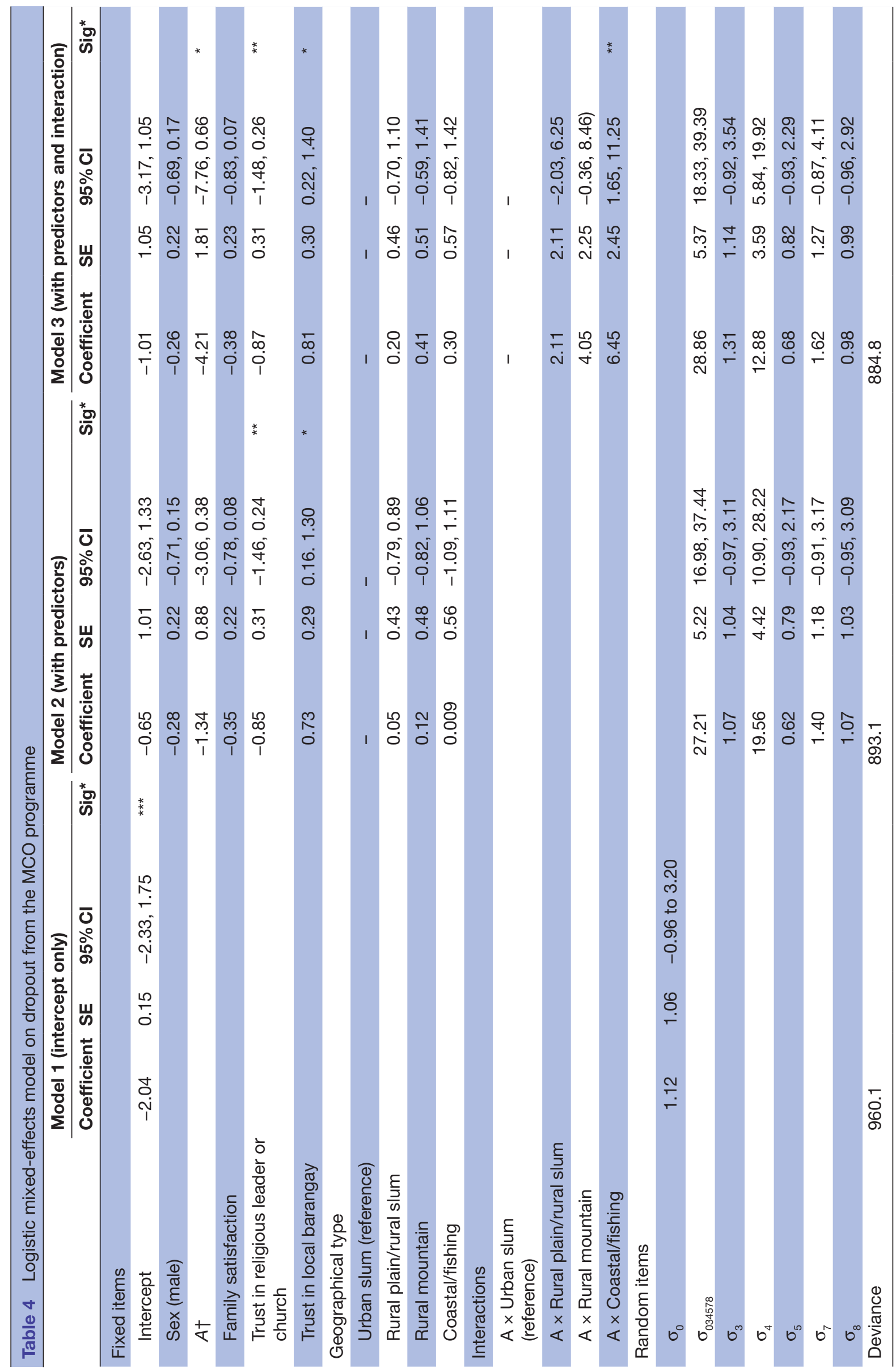




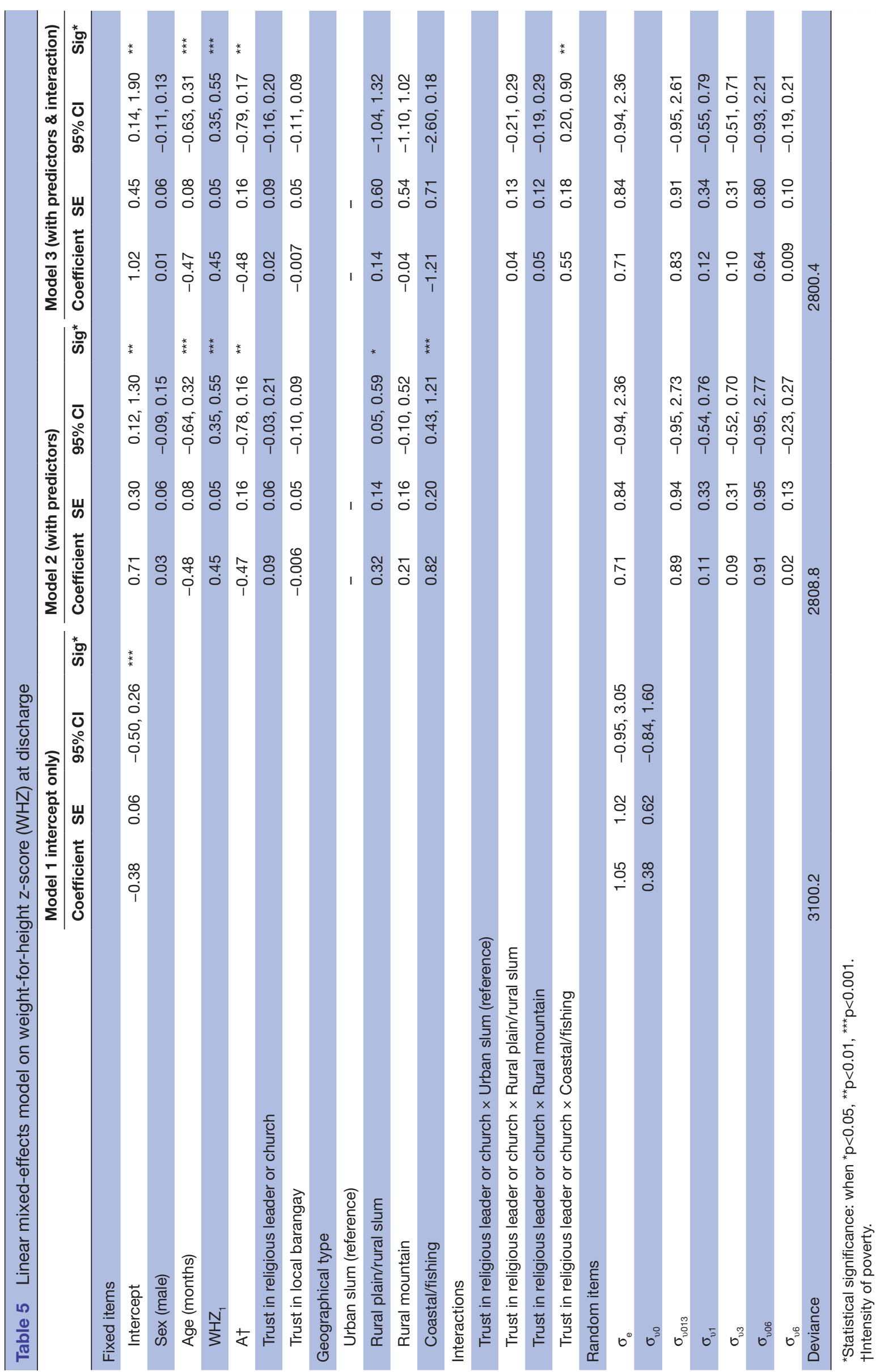


lack of distinction between interpersonal trust in religious leaders and trust in religious institutions in the survey. As a result, we were unable to distinguish between these types of trust within this study. Finally, the sustainability of these results over time could be questioned as the data were collected up to and including May 2013. To address this limitation, future replication studies are planned.

Given the high burden of child malnutrition in the Philippines, there is a need for effective strategies to deliver care for MAM and SAM. Experiences of social exclusion (eg, limited trust in public institutions) have been found to influence health-seeking behaviour and contribute to gaps in healthcare provision. ${ }^{40}$ We suggest that when individuals feel socially excluded from public health services or institutions, providing health services through collaborations between FBOs and trusted religious leaders and institutions can act as a critical alternative. Community-based care offered by FBOs in partnership with local religious leaders and institutions presents an opportunity to engage with and support income poor households with weak social networks. Based on this finding, we suggest that the delivery of healthcare through FBOs that build on pre-existing trusting relationships with local religious leaders and institutions, should be further explored and evaluated.

Acknowledgements We thank Amy Kipp for editing and writing support. We thank Danilo Servano, Orville Quezon, Charlott Torreblanca and all ICM enumerators for the collection of household survey data. We acknowledge Dr Melinda Gill who designed the MCO programme and led ICM's Health Team. Lastly, we acknowledge all of the health staff, guardians, mothers and specifically the children who were involved in the MCO programme.

Contributors LLL: co-lead author, study design, analysis, writing and revision. WD: co-lead author, analysis, writing and revision. HLQ: analysis. DCC: study design, analysis, writing and revision.

Funding The authors have not declared a specific grant for this research from any funding agency in the public, commercial or not-for-profit sectors.

Competing interests Dr LLL reports that LLL and HLQ were paid salaries by ICM as research staff which informs our view on the value of partnerships with religious leaders and institutions in delivering health programmes in income poor settings. They were both given full freedom to publish positive and/or negative results.

Patient consent for publication Not required.

Ethics approval This study was reviewed and approved by the University of Toronto's Research Ethics Board (REB\# 30943).

Provenance and peer review Not commissioned; externally peer reviewed.

Data availability statement Data are available upon reasonable request. All data analysed in this study can be made available upon request.

Open access This is an open access article distributed in accordance with the Creative Commons Attribution Non Commercial (CC BY-NC 4.0) license, which permits others to distribute, remix, adapt, build upon this work non-commercially, and license their derivative works on different terms, provided the original work is properly cited, appropriate credit is given, any changes made indicated, and the use is non-commercial. See: http://creativecommons.org/licenses/by-nc/4.0/.

\section{ORCID iDs}

Lincoln Leehang Lau http://orcid.org/0000-0002-7386-4104

Warren Dodd http://orcid.org/0000-0003-0774-7644

\section{REFERENCES}

1 Duff JF, Buckingham WW. Strengthening of partnerships between the public sector and faith-based groups. Lancet 2015;386:1786-94.

2 Karam A, Clague J, Marshall K, et al. The view from above: faith and health. Lancet 2015;386:e22-4.
3 Lipsky AB. Evaluating the strength of faith: potential comparative advantages of faith-based organizations providing health services in sub-Saharan Africa. Public Adim Dev 2011;31:25-36.

4 Olivier J. Guest editor conclusion: research agenda-setting for faith and health in development - where to now? Dev Pract 2017;27:775-81.

5 Whyle E, Olivier J. Models of engagement between the state and the faith sector in sub-Saharan Africa - a systematic review. Dev Pract 2017;27:684-97.

6 Widmer M, Betran AP, Merialdi M, et al. The role of faith-based organizations in maternal and newborn health care in Africa. Int $J$ Gynaecol Obstet 2011;114:218-22.

7 Olivier J, Tsimpo C, Gemignani R, et al. Understanding the roles of faith-based health-care providers in Africa: review of the evidence with a focus on magnitude, reach, cost, and satisfaction. Lancet 2015;386:1765-75.

8 Tomkins A, Duff J, Fitzgibbon A, et al. Controversies in faith and health care. Lancet 2015;386:1776-85.

9 Rivera-Hernandez $\mathrm{M}$. The role of religious leaders in health promotion for older Mexicans with diabetes. J Relig Health 2015;54:303-15.

10 Kanda K, Jayasinghe A, Silva KT, et al. Religious leaders as potential Advocates for HIV/AIDS prevention among the general population in Sri Lanka. Glob Public Health 2013;8:159-73.

11 Cohen-Dar M, Obeid S. Islamic religious leaders in Israel as social agents for change on health-related issues. J Relig Health 2017;56:2285-96.

12 Adedini SA, Babalola S, Ibeawuchi C, et al. Role of religious leaders in promoting contraceptive use in Nigeria: evidence from the Nigerian urban reproductive health Initiative. Glob Health Sci Pract 2018;6:500-14.

13 Powell CL. Working together for global health goals: the United States agency for international development and Faith-based organizations. CJGH 2014:1:63-70.

14 Sidibé B, Kneip Pelster A, Noble J, et al. Health promotion needs in faith-based organizations: perceptions of religious leaders in Bamako. J Relig Health 2019;58:639-52.

15 Ruark A, Kishoyian J, Bormet M, et al. Increasing family planning access in Kenya through engagement of faith-based health facilities, religious leaders, and community health volunteers. Glob Health $\mathrm{Sci}$ Pract 2019;7:478-90.

16 Save the Children Philippines. Cost of hunger: Philippines. Makati City, Philippines: Save the Children Philippines, 2016.

17 UNICEF WWB. Unicef data: monitoring the situation of children and women: malnutrition data, 2018.

18 Food and Nutrition Research Institute. The double burden of malnutrition in the Philippines. Manila, Philippines: Department of Science and Technology, 2016.

19 Philippine Statistics Authority. Poverty incidence among Fllipinos registered at 21.6\% in 2015 - PSA. Manila, 2016.

20 Asian Development Bank. Poverty in the Philippines Manila: Asian development bank, 2017. Available: https://www.adb.org/countries/ philippines/poverty

21 Summerskill W, Horton R. Faith-based delivery of science-based care. Lancet 2015;386:1709-10.

22 Woolcock M, Narayan D. Social capital: implications for development theory, research, and policy. World Bank Res Obs 2000;15:225-49.

23 Grootaert C, van Bastelaer T. The Role of Social Capital in Development: An Empirical Assessment. Cambridge: Cambridge University Press, 2002.

24 Brehm J, Rahn W. Individual-Level evidence for the causes and consequences of social capital. Am J Pol Sci 1997;41:999-1023.

25 Portes A. Social capital: its origins and applications in modern sociology. Annu Rev Sociol 1998;24:1-24.

26 Hall MA, Dugan E, Zheng B, et al. Trust in physicians and medical institutions: what is it, can it be measured, and does it matter? Milbank Q 2001;79:613-39.

27 Gilson L. Trust and the development of health care as a social institution. Soc Sci Med 2003;56:1453-68.

28 Gilson L. Trust in health care: theoretical perspectives and research needs. J Health Organ Manag 2006;20:359-75.

29 Ozawa S, Sripad P. How do you measure trust in the health system? A systematic review of the literature. Soc Sci Med 2013;91:10-14.

30 WHO. Guideline: updates on the management of severe acute malnutrition in infants and children. Geneva: World Health Organization, 2013.

31 Alkire S, Roche JM, Ballon P, et al. Multidimensional poverty measurement and analysis. Oxford, UK: Oxford University Press, 2015.

32 Cleaver F. The inequality of social capital and the reproduction of chronic poverty. World Dev 2005;33:893-906. 
33 Hung N, Lau LL. The relationship between social capital and selfrated health: a multilevel analysis based on a poverty alleviation program in the Philippines. BMC Public Health 2019;19:1641.

34 Matous P, Ozawa K. Measuring social capital in a Philippine slum. Field methods 2010;22:133-53.

35 Loevinsohn B, Harding A. Buying results? contracting for health service delivery in developing countries. The Lancet 2005;366:676-81.

36 Patouillard E, Goodman CA, Hanson KG, et al. Can working with the private for-profit sector improve utilization of quality health services by the poor? A systematic review of the literature. Int J Equity Health 2007;6:17.
37 Jacobs B, Ir P, Bigdeli M, et al. Addressing access barriers to health services: an analytical framework for selecting appropriate interventions in low-income Asian countries. Health Policy Plan 2012:27:288-300.

38 Whyle EB, Olivier J. Models of public-private engagement for health services delivery and financing in southern Africa: a systematic review. Health Policy Plan 2016;31:1515-29.

39 De Silva MJ, Harpham T. Maternal social capital and child nutritional status in four developing countries. Health Place 2007;13:341-55.

40 Duckett J, Hunt K, Munro N, et al. Does distrust in providers affect health-care utilization in China? Health Policy Plan 2016;31:1001-9. 